\title{
Contenido de aminas biógenas (histamina y tiramina) y su relación con características fisicoquímicas en muestras de chicha de jora elaboradas en la provincia de Abancay, Apurímac
}

RECIBIDO: 25/01/2018 ACEPTADO: 15/08/2018

Julissa Periche PÉReZ ${ }^{1}$

\begin{abstract}
RESUMEN
La chicha de jora, al ser una bebida de fermentación espontánea, no presenta reportes sobre los metabolitos que producen los microorganismos responsables de la fermentación, desconociendo su inocuidad para el consumidor. Ante esta situación, el objetivo de esta investigación fue determinar el contenido de aminas biógenas por HPLC en muestras de la provincia de Abancay (distritos de Abancay y Tamburco), comparar estos valores con los límites permisibles y evaluar la relación del contenido de aminas biógenas y características fisicoquímicas de la chicha de jora. De las 83 muestras analizadas se reportaron concentraciones de hasta $37.53 \mathrm{mg} / \mathrm{L}$ de histamina y 77.95 $\mathrm{mg} / \mathrm{L}$ de Tiramina. En Abancay el $7 \%$ y en Tamburco el $12 \%$ de las muestras reportaron concentraciones superiores al límite permisible de histamina (8 $\mathrm{mg} / \mathrm{L})$; y el $16 \%$ de las muestras en ambos distritos reportaron concentraciones superiores al límite permisible de Tiramina (25 mg/L). En cuanto a la relación con sus características fisicoquímicas, solamente se encontró relación significativa entre el \%Acidez y el contenido de histamina ( $r=0.502)$.
\end{abstract}

Palabras-claves: Aminas biógenas; chicha de jora; histamina; tiramina; Abancay.

BIOLOGICAL AMINE (HISTAMINE AND TYRAMINE) CONTENT AND ITS RELATIONSHIP WITH PHYSICAL-CHEMICAL CHARACTERISTICS OF CHICHA DE JORA SAMPLES PREPARED IN THE PROVINCE OF ABANCAY, APURímaC

\section{ABSTRACT}

Chicha de jora, being a spontaneous fermentation drink, does not offer information about the metabolites produced by the microorganisms responsible for fermentation, thus its innocuousness for consumers is unknown. Given this situation, the aim of this study was to determine the content of biogenic amines in samples from the province of Abancay (districts of Abancay and Tamburco) using HPLC, compare these values with the permissible limits and evaluate the biogenic amine content and physicochemical characteristics of "chicha de jora". Of the 83 samples analyzed, concentrations of up to $37.53 \mathrm{mg} / \mathrm{L}$ of histamine and $77.95 \mathrm{mg} / \mathrm{L}$ of tyramine were reported. $7 \%$ and $12 \%$ of the samples from Abancay and Tamburco respectively reported concentrations above the permissible limit of histamine $(8 \mathrm{mg} / \mathrm{L})$; and $16 \%$ of the samples from both districts reported concentrations above the permissible limit of tyramine $(25 \mathrm{mg} / \mathrm{L})$. For the relationship with its physicochemical characteristics, only a significant relationship was found between acidity percentage and histamine content $(r=0.502)$.

Keywords: Biogenic Amines; chicha de jora; histamine; tyramine; Abancay.

\section{INTRODUCCIÓN}

La chicha de jora es una bebida tradicional consumida en Perú y en otros países sudamericanos desde hace muchos años. En la actualidad, tanto su producción como su consumo han ido disminuyendo por el ingreso de nuevas bebidas industrializadas (INEI, 2015).

Esta bebida durante su elaboración aplica una fermentación espontanea (Montibeller, s.f.), que no permite controlar la naturaleza de los microorganismos responsables de la fermentación según su producción (Decheva, Emilova, Valentinova y Mardik, 2005). Existen trabajos de investigación sobre la industrialización de esta bebida; pero los resultados organolépticos no fueron los esperados (Canales, 2011 y De Florio, 1985).

La carga microbiana encargada de la fermentación, también es responsable de las características organolépticas de la chicha de jora; pero su variedad y falta de control puede generar la existencia de sustancias tóxicas en la bebida, las cuales deben ser estudiadas previo a las pruebas de industrialización que se pretendan hacer a futuro, con el objetivo de obtener una bebida no solo agradable al paladar, si no también inocua.

Las aminas biógenas en concentraciones altas en los alimentos, son consideradas como sustancias tóxicas y en su mayoría se encuentran en productos fermentados (Landete, 2005).

Entre las aminas biógenas con mayor efecto tóxico derivados de sus propiedades vasoactivas, se encuentra la Histamina y Tiramina (Bardocz, s.f.). Aunque no se han establecido oficialmente los límites máximos permitidos de aminas biógenas en bebidas alcohólicas, para el caso del vino se recomienda no superar concentraciones de 8 a $20 \mathrm{mg} / \mathrm{L}$ para histamina y 25 a $40 \mathrm{mg} / \mathrm{L}$ para la Tiramina (Soufleros, Marie-Lyse y Bertrand, 1998).

En Bélgica se analizaron 4 tipos de cerveza de diferentes cervecerías; entre ellas, cervezas de fermentación espontanea, que presentaron concentraciones promedio de Histamina de 11.99 m/L y Tiramina de 28.72 mg/L (Loret, Bianchi, Peulen, Deloyer

1 Ingeniero Agroindustrial - Universidad Nacional Micaela Bastidas de Apurímac, Facultad de Ingeniería, Escuela Académico Profesional de Ingeniería Agroindustria.

E-mail: julissaabigail_5@hotmail.com 
CONTENIDO DE AMINAS BIÓGENAS (HISTAMINA Y TIRAMINA) Y SU RELACIÓN CON CARACTERISTICAS FISICOQUÍMICAS EN MUESTRAS DE CHICHA DE JORA ELABORADAS EN LA PROVINCIA DE ABANCAY, APURIMAC

y Dandrifosse, s.f.). Otra de las bebidas de fermentación espontanea que también presentó concentraciones por encima de los límites permisibles es Boza "elaborado con cereales tales como el maíz» con concentraciones de Tiramina de hasta 82.79 mg/L (Cosansu, 2009);

En base a lo descrito, para la chicha de jora se planteó la hipótesis de la presencia de histamina y tiramina en concentraciones que superan los límites permisibles, y que estos valores pueden estar relacionados a características fisicoquímicas que la bebida presenta.

\section{METODOLOGÍA}

\section{Generalidades}

La ejecución de la investigación incluyó las siguientes actividades:

- Adecuación del método de aminas biógenas. Se determinó el límite de cuantificación y rango de trabajo para el análisis de histamina y tiramina en muestras de chicha de jora

- Exploración del número total de productores de chicha de jora. Tras realizar un recorri- do previo en los distritos de Abancay y Tamburco, se determinó que el número de chicherías es variable debido a la baja demanda de esta bebida y a la temporada del año, por lo cual se decidió recolectar todas las muestras durante el recorrido programado.

- Recolección de muestras. Las muestras fueron recolectadas durante los meses de junio y julio del 2015

- Ejecución de ensayos. Se realizaron los análisis de aminas biógenas (Histamina y Tiramina) y análisis fisicoquímicos (\%Acidez, $\mathrm{pH}$, grado alcohólico y sólidos totales)

Muestras. Las muestras de chicha de jora consideradas en el estudio fueron recolectadas, tras realizar un recorrido completo por los distritos de Abancay y Tamburco; encontrando 82 chicherías en total, 57 en Abancay y 25 en Tamburco.

Estas muestras fueron transportadas a la ciudad de Lima en Coolers a $-18^{\circ} \mathrm{C}$ por 24 horas, luego acondicionados y almacenadas a temperatura de congelación hasta el momento de sus análisis.

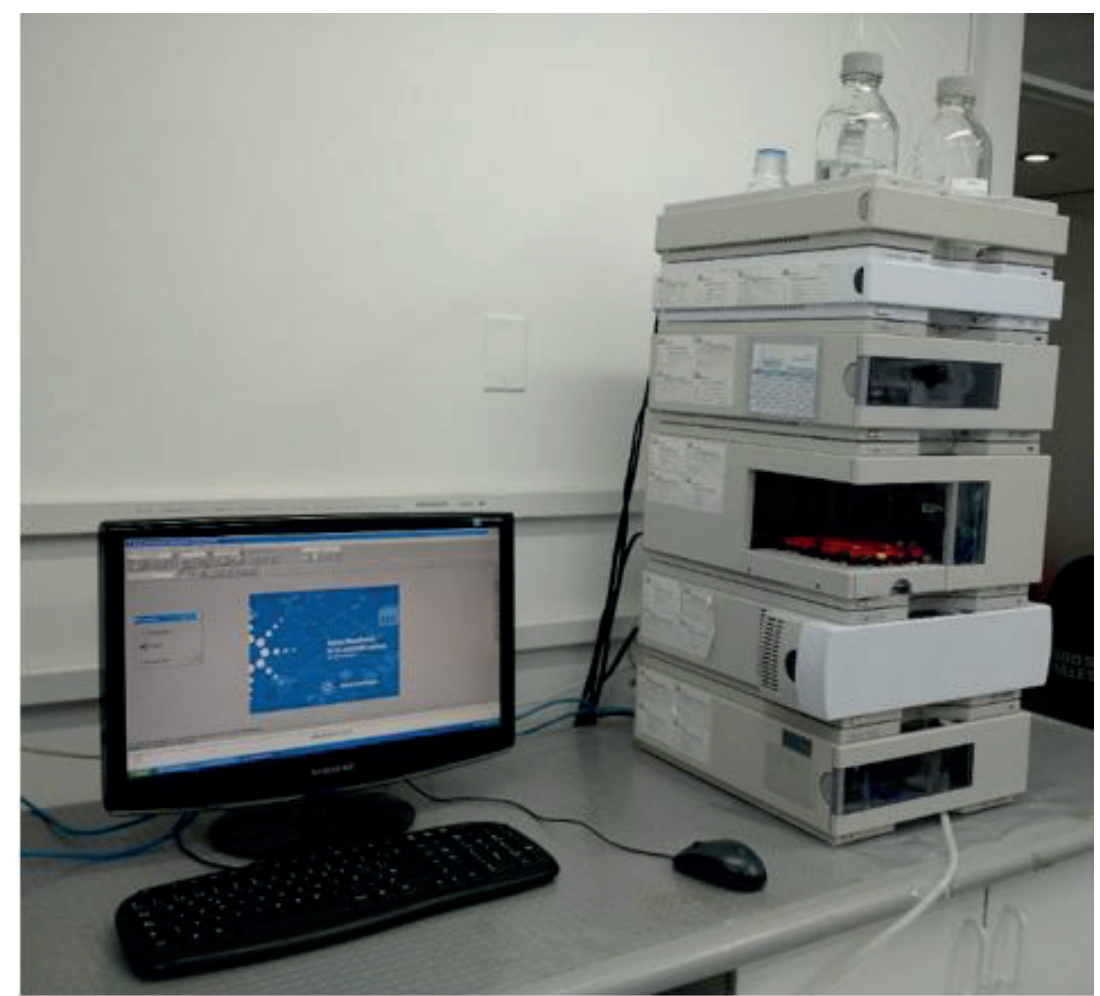

Figura 1. Cromatógrafo líquido (1100 Serie - Agilent Technology) - HPLC Fuente: Elaboración Propia (2015) 
Equipos. Cromatógrafo líquido (1100 Serie - Agilent Technology) con bomba cuaternaria y detector de arreglo de diodos. Condiciones cromatográficas:

- Columna: RP $18 \mathrm{e}\left(125 \mathrm{~mm}^{\star} 4 \mathrm{~mm}^{\star} 5 \mu \mathrm{m}\right)$

- Fase Móvil: Metanol- Agua (80:20)

- Bomba: Isocrática

- Flujo: $1 \mathrm{ml} / \mathrm{min}$

- Volumen de inyección: $20 \mu \mathrm{l}$

- Detección: $254 \mathrm{~nm}$

- Temperatura: $30^{\circ} \mathrm{C}$

\section{Ejecución de ensayos.}

- Histamina y Tiramina (NCh 2637. Of 2001). La descripción del ensayo se muestra en la Figura 2.

- A $5 \mathrm{~g}$ de muestra se le agregó $10 \mathrm{~mL}$ de ácido tricloroacetico al $5 \%$. Se agitó en el Shaker por 30 minutos, y el sobrenadante se centrifugó por 15 minutos a 3000rpm. Se filtró y re-filtró el sobrenadante con papel Whatman \#4 y filtros de membrana de $0.45 \mu \mathrm{m}$ respectivamente.
- Se prepararon las soluciones estándar de tiramina e histamina de $1000 \mathrm{mg} / \mathrm{L}$ cada una en ácido tricloroacetico al $5 \%$. De estas soluciones madre se prepararon soluciones de trabajo de 2, 4, 8, 16, 32 y $40 \mathrm{mg} / \mathrm{L}$ para tiramina y $0.5,1,2,4,8$ y $10 \mathrm{mg} / \mathrm{L}$ para histamina.

- Los extractos de muestras, conjuntamente con las soluciones estándar fueron derivatizadas con cloruro de dansilo, añadiendo secuencialmente lo siguiente:

- $100 \mu \mathrm{L}$ de extracto de muestra o solución estándar

- $400 \mu \mathrm{L}$ de solución de bicarbonato de sodio $0.25 \mathrm{M}$

- $200 \mu \mathrm{L}$ de solución de cloruro de dansilo $10 \mathrm{mg} / \mathrm{mL}$.

- $300 \mu \mathrm{L}$ de solución de bicarbonato de sodio $0.25 \mathrm{M}$

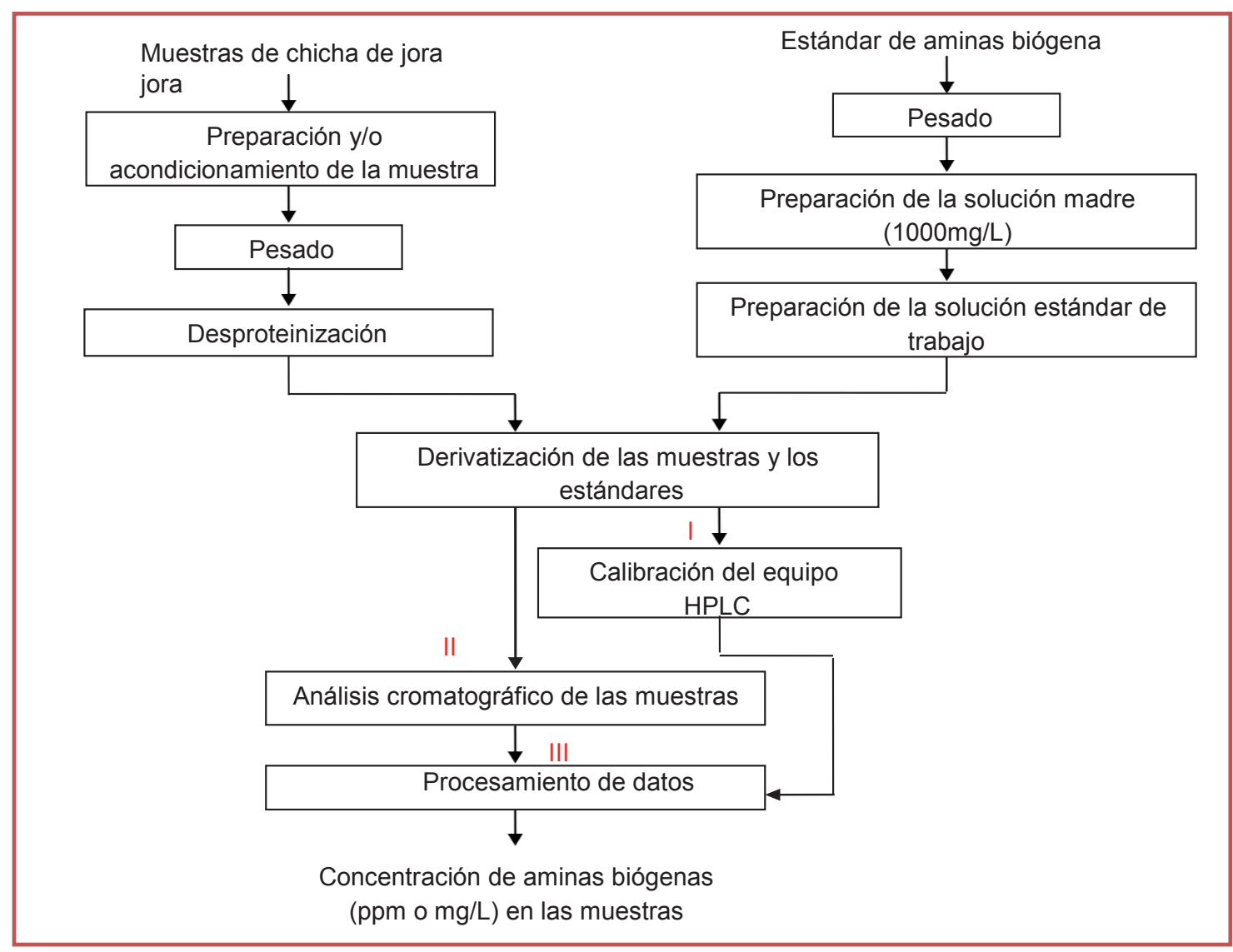

Figura 2. Proceso seguido para la determinación de aminas biógenas

Fuente: Elaboración Propia (2015) 
- Los derivatizados se incubaron a $60^{\circ} \mathrm{C}$ por 1 hora en un baño maría. Se enfriaron a temperatura ambiente. Y las muestras fueron inyectadas en el equipo HPLC.

- \%Acidez (AOAC Official Method 950.07). 50 $\mathrm{mL}$ de las muestras desgasificadas fueron tituladas con solución de hidróxido de sodio $0.1 \mathrm{~N}$ estandarizada. El punto final fue evaluado con el valor de $\mathrm{pH}$, siendo aceptable de 8.1 a 8.3 .

- pH (AOAC Official Method 945.10). A $50 \mathrm{~mL}$ de las muestras desgacificadas de chicha de jora se introdujo el sensor de $\mathrm{pH}$ (previamente calibrado con Buffer de $\mathrm{pH} 4$ y 7 ) y se realizaron las lecturas.

- Grado alcohólico (AOAC Official Method 935.21). Se pesó una fiola de $100 \mathrm{~mL}$. Luego se agregó agua desionizada $\left(20^{\circ} \mathrm{C}\right)$ y se registró el peso. A la misma fiola seca, se le agregó la muestra de chicha de jora $\left(20^{\circ} \mathrm{C}\right)$ y se pesó. Esta muestra fue colocada en un sistema de destilación con la ayuda de $30 \mathrm{~mL}$ de agua. El destilado se recibió en la misma fiola y se pesó a $20^{\circ} \mathrm{C}$.

- Sólidos totales (NOM-116-SSA1-1994). En una placa vacía se pesaron alrededor de $4 \mathrm{~g}$ de arena purificada y se colocó en la estufa a $100^{\circ} \mathrm{C}$ por 2 horas. En la placa acondicionada se pesaron entre 2 y $6 \mathrm{~g}$ de muestra de chicha de jora previamente preparada. Se mezcló bien con la arena y se llevó al baño maría a $90^{\circ} \mathrm{C}$ hasta sequedad. Las muestras del baño maría se llevaron a la estufa por 4 horas a $100^{\circ} \mathrm{C}$.

\section{Medidas de control}

Cada muestra fue analizada por duplicado y aleatoriamente se introdujeron muestras adicionadas con solución estándar de las aminas biógenas en estudio, como sistema de aseguramiento de la calidad de resultados.

\section{RESULTADOS Y DISCUSIONES}

\section{CONTENIDO DE AMINAS BIÓGENAS EN ABANCAY Y TAMBURCO}

\section{Contenido de aminas biógenas/ Cuantificación}

En la evaluación de resultados, se evidenció la presencia de picos cromatográficos de histamina y tiramina (Figura 3, 4 y 5). En estas figuras, el eje " $Y$ " es una medida de la intensidad de la absorbancia (en unidades de mAU o unidades de mili-absorbancia); el eje $X$ esta en unidades de tiempo (generalmente minutos), y se usa para determinar el tiempo de retención (tR) para cada pico.

Los picos cromatograficos fueron cuantificados con el uso de estándares de aminas biogenas de concentración conocida, y tras el cálculo respectivo se obtuvieron los valores presentados en la Figura 6 y 7.

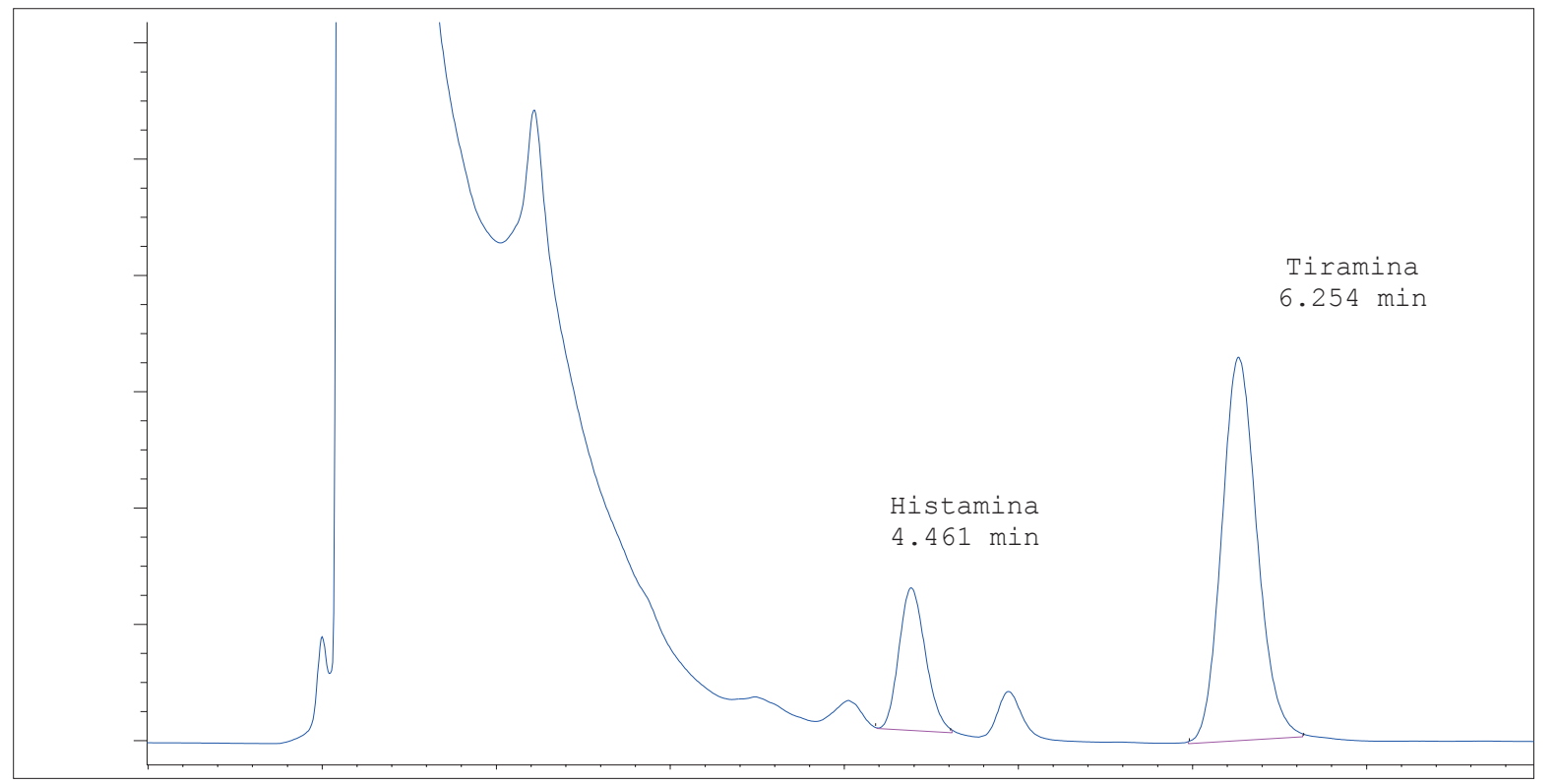

Figura 3. Picos cromatográficos de la solución estándar de histamina y tiramina /// Eje "Y": intensidad de absorbancia (mAU); y el eje "X": tiempo (minutos)

Fuente: Elaboración Propia (2015) 


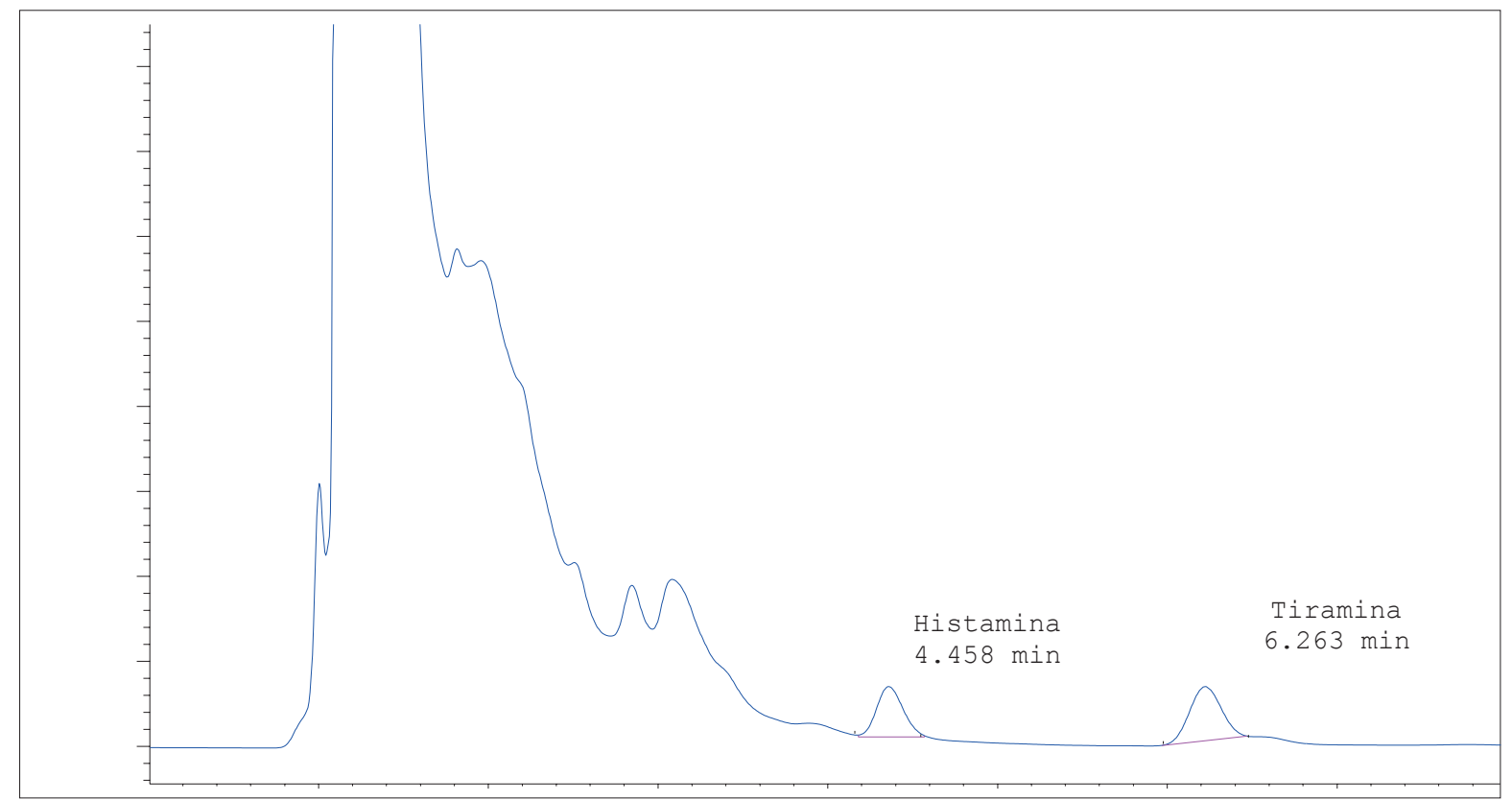

Figura 4. Picos cromatográficos de una de las muestra de chicha de jora en estudio /// Eje "Y": intensidad de absorbancia (mAU); y el eje "X": tiempo (minutos) /// Procedencia de la muestra: distrito de Tamburco /// Numero de muestras analizadas por distrito: 25

Fuente: Elaboración Propia (2015)

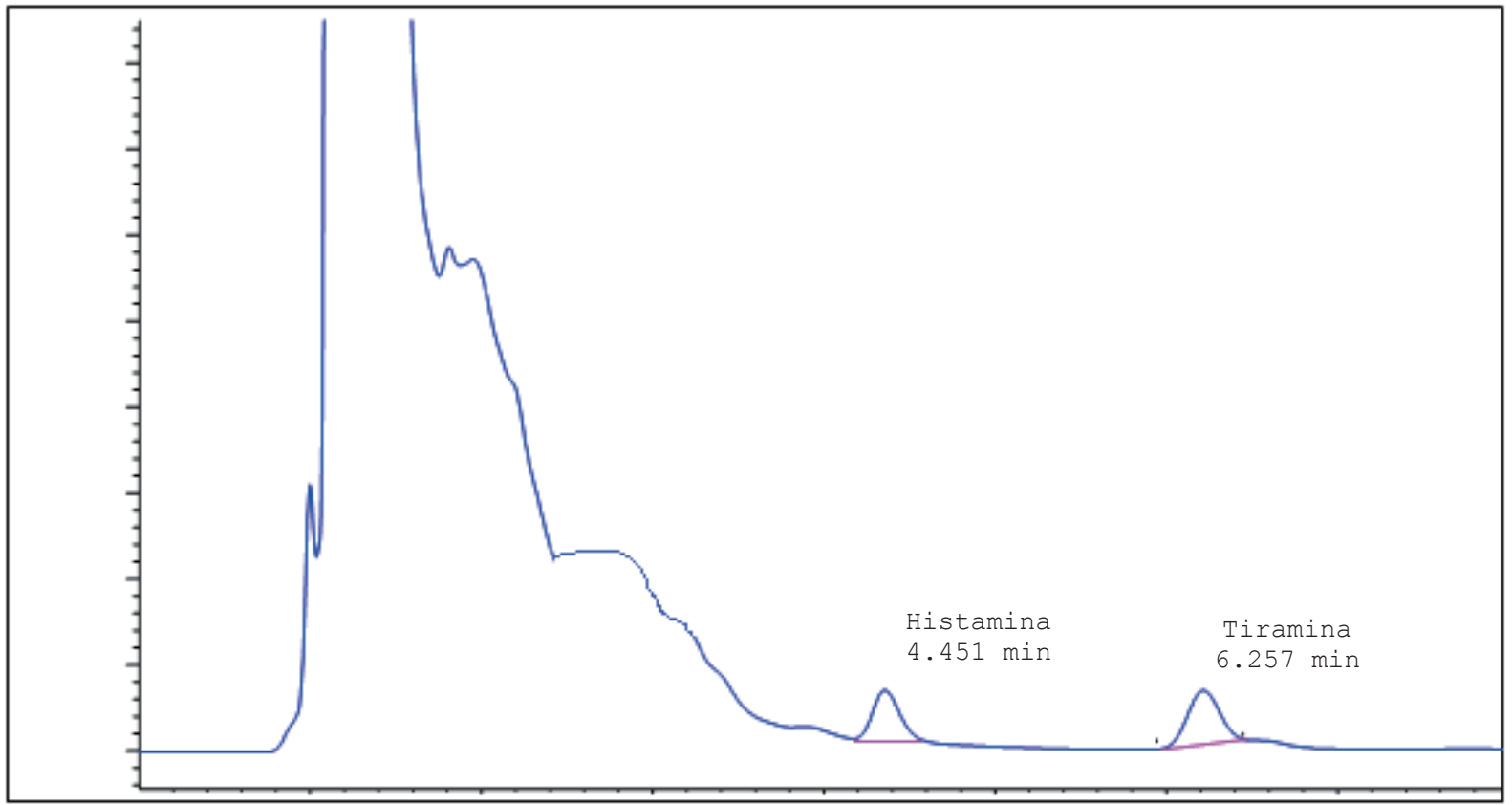

Figura 5. Picos cromatográficos de una de las muestra de chicha de jora en estudio /// Eje "Y": intensidad de absorbancia (mAU); y el eje "X": tiempo (minutos) /// Procedencia de la muestra: distrito de Abancay /// Numero de muestras analizadas por distritoñ: 57

Fuente: Elaboración Propia (2015) 
Contenido de AMINAS BIÓGenAs (HISTAMINA Y TIRAMINA) Y SU RELACIÓN CON CARACTERISTICAS FIIICOQUIMIICAS EN MUESTRAS DE CHICHA DE JORA ELABORADAS EN LA PROVINCIA DE ABANCAY, APURIMAC

- Histamina $(\mathrm{mg} / \mathrm{L}) \quad$ Tiramina $(\mathrm{mg} / \mathrm{L}$

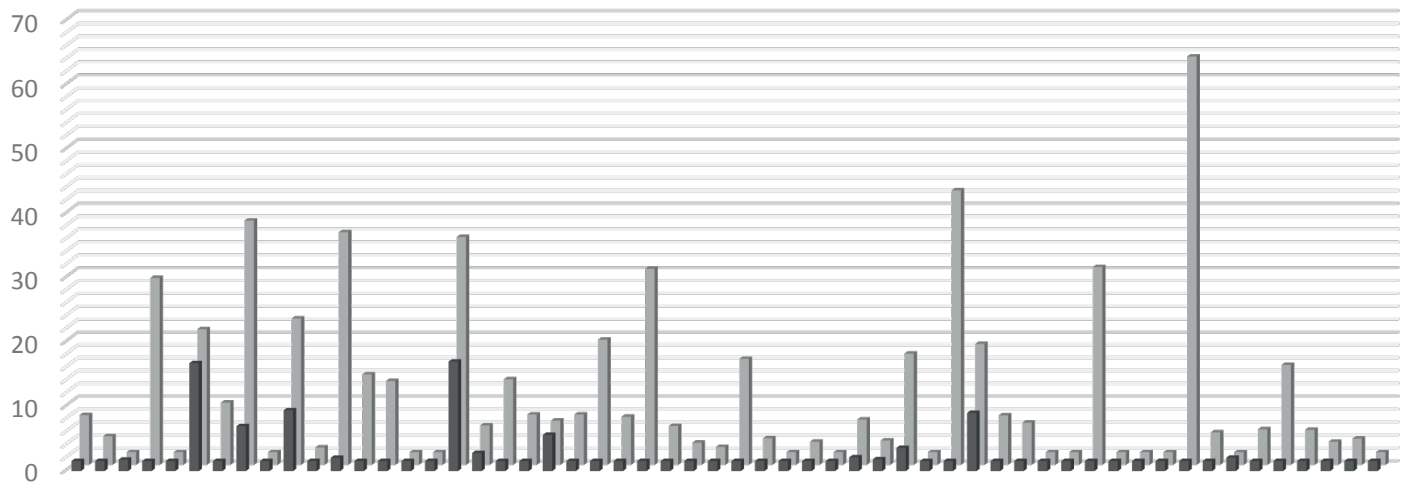

Figura 6. Representación gráfica del contenido (mg/L) de Histamina y Tiramina en las muestras de Chicha de Jora del distrito de Abancay

Fuente: Elaboración Propia (2015)

- Histamina $(\mathrm{mg} / \mathrm{L}) \quad$ - Tiramina $(\mathrm{mg} / \mathrm{L})$

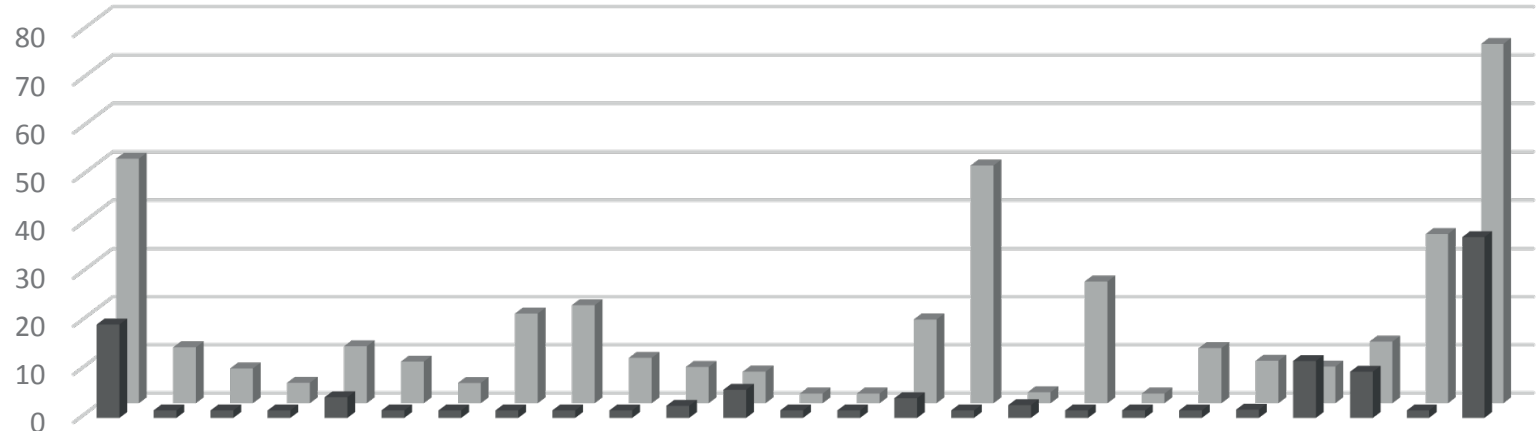

Figura 7. Representación gráfica del contenido (mg/L) de Histamina y Tiramina en las muestras de Chicha de Jora del distrito de Tamburco

Fuente: Elaboración Propia (2015) 


\section{Contenido de aminas biógenas/ límites permisi- bles}

Con un $95 \%$ de nivel de confianza, los resultados de las muestras de chicha de jora en estudio fueron comparados estadísticamente con la concentración límite permisible para cada amina biógena (se utilizó el valor mínimo dentro del rango expuesto); 8 $\mathrm{mg} / \mathrm{L}$ para histamina y $25 \mathrm{mg} / \mathrm{L}$ para la tiramina, según lo indicado por Soufleros et al. (1998), quien reportó que estas concentraciones pueden causar efectos fisiológicos negativos tras el consumo de muestras de vino.

La evaluación previa se ejecutó aplicando ANOVA de 1 factor para cada distrito, realizando el contraste de la hipótesis nula (todas las muestras tienen igual concentración de aminas biógenas) y la hipótesis alterna (al menos una de las muestras presenta diferente concentración de aminas biógenas). Los resultados obtenidos se muestran en la Tabla1.

En base a las conclusiones obtenidas, se procedió a realizar una segunda evaluación con la finalidad de conocer las diferencias en la concentración de aminas biógenas y verificar cuantas muestras superan el valor límite permisible previamente establecido. Para esta evaluación se aplicó la Prueba
Tukey al 95\% de confianza, obteniendo los resultados de la Tabla 2.

En la Tabla 3 se muestra un resumen de datos obtenidos durante la investigación

Los valores máximos obtenidos superaron los límites permisibles. Situación similar al estudio sobre el contenido de tiramina y otras aminas en Boza «bebida fermentada de cereales que tiene como uno de sus ingredientes al maíz», donde se reportaron concentraciones de hasta $82.79 \mathrm{mg} / \mathrm{L}$ de Tiramina (Cosansu, 2009). Los resultados reportados en ambos trabajos de investigación remarcan la importancia de la evaluación del contenido de aminas biógenas en bebidas de fermentación espontanea, y así evitar el riesgo de producir daños al consumidor.

Para el caso de la histamina, la Boza sólo reportó valores hasta $4.07 \mathrm{mg} / \mathrm{L}$ (Cosansu, 2009). Esta diferencia puede estar relacionada a características propias de cada bebida o a las prácticas de manufactura aplicada para la elaboración, tal es el caso del estudio de comparación entre diferentes tipos de cerveza, donde se concluyó que la cerveza de fermentación espontánea, presenta la mayor concentración de histamina, tiramina y otras aminas biógenas; pero no todas las cervecerías en estudio

Tabla 1. Comparación del contenido de aminas biógenas por muestra

\begin{tabular}{|c|c|c|c|}
\hline Comparación & Distrito & Valor $\mathbf{P}$ & Conclusión \\
\hline Histamina vs muestra & Abancay & 0.000 & Al menos una de las muestras presenta diferente concentración \\
\hline Tiramina vs muestra & Abancay & 0.000 & Al menos una de las muestras presenta diferente concentración \\
\hline Histamina vs muestra & Tamburco & 0.000 & Al menos una de las muestras presenta diferente concentración \\
\hline Tiramina vs muestra & Tamburco & 0.000 & Al menos una de las muestras presenta diferente concentración \\
\hline
\end{tabular}

Tabla 2. Prueba Tukey, agrupación por concentración de aminas biógenas

\begin{tabular}{|c|c|c|c|}
\hline Aminas biógenas & Distrito & \# grupos & $\begin{array}{c}\text { \# muestras, estadísticamente mayor al } \\
\text { límite permisible }\end{array}$ \\
\hline Histamina & Abancay & 9 & 4 \\
\hline Tiramina & Abancay & 23 & 9 \\
\hline Histamina & Tamburco & 9 & 4 \\
\hline Tiramina & Tamburco & 12 & 4 \\
\hline
\end{tabular}

Tabla 3. Resumen de resultados

\begin{tabular}{|c|c|c|c|}
\hline Amina biógena (distrito) & Cantidad de muestras analizadas & Valor máximo & $\begin{array}{c}\% \text { muestras que superan los } \\
\text { límites permisibles* }\end{array}$ \\
\hline Histamina (Abancay) & 57 & $16.99 \mathrm{mg} / \mathrm{L}$ & $7 \%$ \\
\hline Histamina (Tamburco) & 25 & $37.53 \mathrm{mg} / \mathrm{L}$ & $12 \%$ \\
\hline Tiramina (Abancay) & 57 & $77.95 \mathrm{mg} / \mathrm{L}$ & $16 \%$ \\
\hline Tiramina (Tamburco) & 25 & $74.44 \mathrm{mg} / \mathrm{L}$ & $16 \%$ \\
\hline
\end{tabular}

$\left(^{*}\right) 8 \mathrm{mg} / \mathrm{L}$ para histamina y $25 \mathrm{mg} / \mathrm{L}$ para tiramina 
CONTENIDO DE AMINAS BIÓGENAS (HISTAMINA Y TIRAMINA) Y SU RELACIÓN CON CARACTERISTICAS FISICOQUÍMICAS EN MUESTRAS DE CHICHA DE JORA ELABORADAS EN LA PROVINCIA DE ABANCAY, APURIMAC

mostraron bebidas con alarmantes niveles de estas sustancias (Loret et al., s.f.).

Analizando los resultados obtenidos, se presume que el bajo porcentaje de muestras que superaron los límites permisibles, puede estar relacionado a la presencia de Lactobacillus plantarum en la chicha de jora (Quillama, Pasteris y Manca de Nadra, 1996. Última investigación realizada a la fecha de redacción del presente artículo). Teniendo en cuenta que esta bacteria es productora de bacteriocinas con capacidad de inhibición de Bacillus cereus, Staphylococcus aureus, Salmonella sp. (Huamán, 2013), y bacterias lácticas (Quillama, 1998. Última investigación realizada a la fecha de redacción del presente artículo); microorganismos que en su mayoría están relacionados con la formación de aminas biógenas (Fernández y Alvares, 2005). Adicionalmente, en una evaluación de las especies de bacterias lácticas capaces de sintetizar aminas biógenas en vino, se concluyó que Lactobacillus plantarum no es productor de histamina y para el caso de la tiramina, menos del $1 \%$ de Lactobacillus plantarum encontrados son productores de esta amina biógena (Molenaar et al., 1993 citado por EFSA., 2011).

\section{CARACTERÍSTICAS FISICOQUÍMICAS DE LA CHICHA DE JORA}

\section{Resultados para el análisis de parámetros fisi- coquímicos}

Todas las muestras de chicha de jora recolectadas fueron analizadas, y se resumen los resultados en la Tabla 4.

Los valores obtenidos para $\mathrm{pH}$ y acidez, están incluidos en el rango de concentración reportado en muestras de fermentación espontanea provenientes del Valle del Mantaro - Huancayo (García-Ventocilla, 2008). Los valores del grado alcohólico en el rango de concentración reportado en muestras de fermentación espontanea provenientes de Arequipa, Cusco, Piura y Lima (Manrique, 1979. Última investigación realizada a la fecha de redacción del presente artículo). La densidad promedio obtenida es similar al reportado en muestras de fermentación espontanea provenientes de Catacaos y Sullana (Gonzales, 1987. Última investigación realizada a la fecha de redacción del presente artículo).

Estos datos permiten concluir que las características fisicoquímicas de esta bebida milenaria, son similares en diferentes lugares del Perú, planteando la hipótesis de que el método de preparación es equivalente; pero la antigüedad de las referencias es una limitante que debe ser subsanada con nuevos trabajos de investigación sobre la caracterización de muestras de chicha de jora de fermentación espontanea.

\section{Relación entre el contenido de aminas biógenas y parámetros fisicoquímicos}

Se estudiaron los coeficientes de correlación al $95 \%$ de nivel de confianza entre la histamina, tiramina, y el resto de parámetros analizados con el fin de determinar una posible relación entre ellos. Utilizando la prueba de Análisis de regresión, se realizó el contraste de la hipótesis nula $(P>0.05$, coeficiente de correlación es igual a cero) y la hipótesis alterna $(P<0.05$, coeficiente de correlación es diferente de cero).

Las comparaciones que presentaron valores de coeficientes de correlación $(r)$ significativamente diferentes de cero $(P<0,05)$, son aquellas que presentan un grado de relación considerable y son mostrados en la Tabla 5.

El grado de correlación entre la histamina y la tiramina en las muestras de chicha de jora en estudio fue mayor que el reportado en el análisis de aminas biógenas en muestras de sidra [r=0.67] (Garai-lba-

Tabla 4. Resumen de resultados de parámetros fisicoquímicos

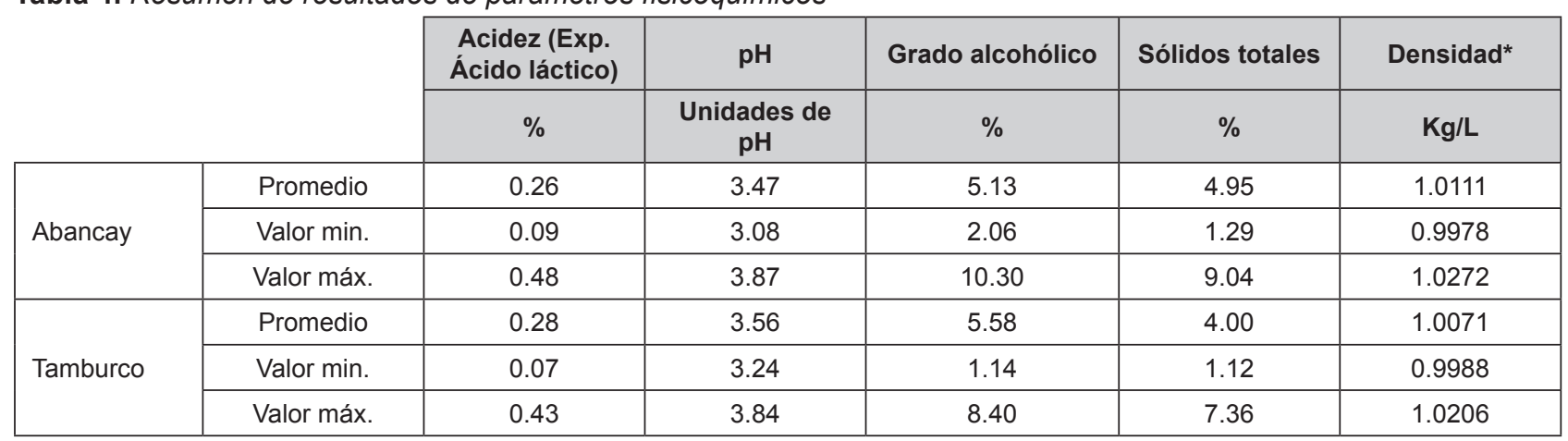

*calculado con algunos datos de grado alcohólico 
Tabla 5. Relación entre aminas biógenas y parámetros fisicoquímicos

\begin{tabular}{|c|c|c|c|}
\hline Variables (Comparación) & $\begin{array}{c}\text { Coeficiente de } \\
\text { correlación }(\mathbf{r})\end{array}$ & Ecuación modelo matemático & $\begin{array}{c}\text { \%Confianza del modelo } \\
\text { matemático }\left(\mathbf{R}^{2}\right)\end{array}$ \\
\hline Histamina - Tiramina & 0.803 & Tiramina $=6.23+1.67$ (Histamina) & $62.7 \%$ \\
\hline Histamina - \%Acidez & 0.502 & Histamina $=-5.24+45.3(\%$ Acidez) & $21.9 \%$ \\
\hline Histamina - pH & --- & --- & -- \\
\hline Histamina - Grado alcohólico & --- & --- & -- \\
\hline Histamina - sólidos totales & --- & --- & -- \\
\hline Tiramina - \%Acidez & --- & --- & -- \\
\hline Tiramina - pH & --- & --- & - \\
\hline Tiramina - Grado alcohólico & --- & --- & - \\
\hline Tiramina - sólidos totales & --- & - & - \\
\hline
\end{tabular}

(--) indica que no se obtuvo una correlación estadísticamente significativa $(P>0.05)$

Nota: Para los parámetros de sólidos totales y densidad, se presentó un alto grado de correlación entre sí, con un coeficiente de correlación $r=0.953$ y un modelo matemático con un $90.74 \%$ de confianza «densidad $=0.004 \%$ Sólidos totales +0.9916 »

be, 2010). Estas diferencias hacen presumir que la dependencia Histamina - Tiramina también está influenciada por el tipo de alimento en el que se desarrollan las aminas biógenas. El alto grado de correlación puede ser indicativo de la presencia de un microorganismo con capacidad descarboxilante para ambas aminas biógenas en las muestras analizadas (Loret et al., s.f.).

A pesar de que el coeficiente de correlación presentado para la comparación Histamina - \%Acidez es significativa ( $r=0.502)$, el modelo matemático obtenido, sólo presentó un $21.9 \%$ de confianza, lo que permite concluir que el nivel de relación entre ambos parámetros es baja y no es representativa para las muestras de chicha de jora en estudio.

En cervezas europeas se ha reportado que el contenido de histamina y tiramina fueron mayores en cervezas con altos valores de acidez total y de $\mathrm{pH}$ (Camacho et al., 2007); sin embargo, en un estudio de aminas biógenas en muestra de boza «bebida fermentada que incluye maíz entre sus ingredientes», no se encontró relación significativa entre las aminas biógenas estudiadas y el valor de $\mathrm{pH}$ (Yegin y Uren, 2008), tan igual como los resultados obtenidos en este trabajo de investigación. De manera general, se menciona que un alto valor de $\mathrm{pH}$ aumentaría el contenido de aminas biógenas (Gardini et al., 2005 citado por Garai-lbabe, 2010); ya que el nivel del $\mathrm{pH}$ es un factor importante que influye en la actividad de descarboxilación del aminoácido (Silla Santos, 1996 citado por EFSA, 2011), siendo el pH óptimo para la actividad amino descarboxilasa entre 4,0 y 5,5 (Halász et al., 1994 citado por Karovicova y Kohajdova, 2003). Sin embargo, hay dos mecanismos relacionados al pH que actúan si- multáneamente, uno provoca el incremento de la acidez qué inhibe el crecimiento de microorganismos (Maijala et al., 1993 citado por EFSA, 2011), y el otro afecta la producción y actividad de la enzima porque en un ambiente de $\mathrm{pH}$ bajo, se estimulan las bacterias para producir más enzimas descarboxilasas como parte de su mecanismo de defensa contra la acidez (Molenaar et al., 1993 citado por EFSA, 2011). Estos factores contrarios interfieren entre sí y el resultado neto depende de su equilibrio (EFSA., 2011).

En un trabajo de investigación, sobre la cerveza, se observó que las muestras menos fermentadas tenían los mayores contenidos de histamina; sin embargo, no presentaron una correlación significativa entre el nivel de histamina o tiramina y el contenido de alcohol (Landete, 2005). En otro estudio, se reportó que el etanol presente en el vino también influye en la concentración de histamina, encontrando que cuando las concentraciones superaban el $10 \% \mathrm{v} / \mathrm{v}$ de etanol se observaba una disminución en la población microbiana y por tanto en los niveles de histamina; sin embargo cuando los niveles de etanol eran iguales o inferiores al $10 \% \mathrm{v} / \mathrm{v}$, se encontró que la producción de histamina aumentaba con la concentración alcohólica; concluyendo que la actividad del enzima descarboxilasa se ve favorecida por la presencia de etanol hasta cierto grado alcohólico (Camacho et al., 2007).

Tan igual como en las muestras de chicha de jora en estudio, no se han reportado correlación significativa entre histamina o tiramina y la materia seca total en muestra de boza, «bebida fermentada que incluye maíz entre sus ingredientes» (Yegin y Uren, 2008). 


\section{CONCLUSIONES}

- Las muestras en estudio presentaron concentraciones de hasta $37.53 \mathrm{mg} / \mathrm{L}$ para histamina y $77.96 \mathrm{mg} / \mathrm{L}$ para tiramina.

- Al realizar la evaluación estadística a un 95\% de nivel de confianza se encontró que, el $7 \%$ y el $16 \%$ de las muestras del distrito de Abancay superaron los límites permisibles de Histamina (8 mg/L) y Tiramina $(25 \mathrm{mg} / \mathrm{L})$ respectivamente, y en Tamburco, fue el $12 \%$ para Histamina y el $16 \%$ para Tiramina.

- Se obtuvieron valores del pH entre 3.08 y $3.87, \%$ acidez entre $0.07 \%$ y $0.48 \%$, grado alcohólico entre $1.14 \%$ y $10.30 \%$, \% sólidos totales entre $1.12 \%$ y $9.04 \%$ y densidad entre 0.9978 y 1.0272 . Únicamente se presentó una relación significativa $(P<0.05)$ del $\%$ Acidez con la concentración de Histamina, mostrando un coeficiente de correlación $r=$ 0.502; sin embargo el \%confianza del modelo matemático obtenido es bajo (21.9\%).

- Para los parámetros de sólidos totales y densidad, se presentó un alto grado de correlación entre sí, con un coeficiente de correlación $r=0.953$ y un modelo matemático con un $90.74 \%$ de confianza «densidad = $0.004 * \%$ Sólidos totales $+0.9916 »$

\section{RECOMENDACIONES}

- Evaluar la influencia del proceso de elaboración de la chicha de jora en la producción de aminas biógenas en la bebida.

- Aislar los microrganismos encargados de la fermentación de la chicha de jora, evaluar su capacidad descarboxilante y su relación con la producción de aminas biógenas.

- Determinar el grado de toxicidad de la chicha de jora con una determinada concentración de aminas biógenas para establecer el límite máximo permisible para el consumo (similar al realizado para el vino).

- Evaluar si hay un componente propio de la chicha de jora que evita la síntesis de aminas biógenas.

\section{REFERENCIAS BIBLIOGRÁFICAS}

[1] Bardocz, S. (s.f.). Role of biogenic amines summing up or what is it we do not know?. En S., Bardocz; J.,Koninkx; M.,Grillo y A.,White.
(Eds.). (1999). Biologically active amines in food: Biologically active amines in food processing and amines produced by bacteria, and polyamines and tumour growth. (3): $1-5$. Belgium: COST 917 - European Commission.

[2] Camacho, M.; Torres, G.; Izquierdo, P.; Benitez, B.; Allara, M. y Céspedes, E. (2007). Determinación de Aminas Biógenas en Cervezas que se expenden en la Ciudad de Maracaibo - Venezuela. Revista Multiciencias, 7 (3), $276-281$.

[3] Cosansu, S. (2009). Determination of biogenic amines in a fermented beverage, boza. Journal of Food, Agriculture \& Environment, 7 (2): 54 $-58$.

[4] Canales, M. (2011). Estudio de estabilización de la Chicha de Jora. (Tesis para optar el título profesional de Ingeniero en Industrias Alimentarias). Universidad Nacional Agraria La Molina. Lima - Perú.

[5] Decheva, I.; Emilova, L.; Valentinova, M. y Mardik, N. (2005). The Boza - a Traditional and Modern Beverage. Bulgaria. Recuperado de http://bgthielman.us/recipes/boza/Boza-en.pdf

[6] De Florio, E. (1985). Estudio de la fermentación de la Chicha de Jora. (Tesis presentada para optar el título de Ingeniero en Industrias Alimentarias). UNALM. Lima - Perú.

[7] EFSA, (2011). Scientific Opinion on risk based control of biogenic amine formation in fermented foods. EFSA Journal, 9 (10): 1 - 93. doi:10.2903/j.efsa.2011.2393.

[8] Fernández, M. y Alvares, M. (2005). Las aminas biógenas en los alimentos. CTC Alimentación 26, 84-90. ISSN 1577-5917.

[9] Garai-lbabe, G. (2010). Bacterias lácticas de sidra natural: implicación en alteraciones y potencial probiótico de cepas productoras de $(1,3)(1,2)-\beta-D$-glucanos. (Tesis Doctoral). Universidad del País Vasco. Vitoria-Gasteiz.

[10] García-Ventocilla, D. y Mamani, G. (2008). Selección de levaduras nativas Saccharomyces cerevisiae aisladas de chicha de jora del Valle del Mantaro. Tesis para optar el título profesional de Ingeniero en Industrias Alimentarias. Universidad Nacional del Centro del Perú. Huancayo - Perú.

[11] Gerardo, O. (2007). Avatares de la Chicha. POLIGRAMAS, 27, 1 - 16.

[12] Karovicova, J. y Kohajdova, Z. (2003). Biogenic Amines in Food. Chem. Pap. 59 (1): 70 - 79. 
[13] Huamán, N. (2013). Producción de bacteriocina utilizando como sustrato de chicha de jora y evaluación de su capacidad inhibitoria in vitro en bacterias patógenas (Bacillus cereus, Staphylococcus aureus y Salmonella sp.) causantes del deterioro de alimentos. (Tesis para optar al Título profesional de Ingeniero Agroindustrial). Universidad Nacional Micaela Bastidas de Apurímac. Perú.

[14] INEI, (2015). Situación de Salud de la Población Adulta Mayor

[15] Landete, J. M. (2005). Estudio y caracterización molecular de la producción de aminas biógenas por parte de bacterias lácticas de origen enológico. (Tesis doctoral). Universidad de Valencia. España.

[16] Loret, S.; Bianchi, D.; Peulen, O.; Deloyer, P. y Dandrifosse, G. (s.f.). Biogenic amines in different types of Belgian beers: a first survey. En S., Bardocz; J.,Koninkx; M., Grillo y A., White. (Eds.). (1999). Biologically active amines in food: Biologically active amines in food processing and amines produced by bacteria, and polyamines and tumour growth. (3): 1 - 5 . Belgium: COST 917 - European Commission.

[17] Manrique, I. (1979). Especies bacterianas en la Chicha de Jora. Anales científicos UNA. XVII (1-4): 9 - 18.

[18] Quillama,E.(1998). Produccióndebacteriocinas por cepas de Lactobacillus aisladas de chicha de jora. (Tesis para optar al grado académico de Magister en Microbiología). Universidad Nacional Mayor de San Marcos. Lima - Perú.

[19] Quillama, E.; Pasteris, S. y Manca de Nadra, M. (1996). Las bacterias lácticas y la Chicha de Jora. Revista Pura Selva, 142: 12- 13.

[20] Soufleros, E.; Marie-Lyse, B. y Bertrand A. (1998). Correlation between the content of biogenic amines and other wine compounds. American Journal of Enology and Viticulture. 49, 266-277

[21] Yegin, S. y Uren, A. (2008). Biogenic amine content of boza: A traditional cereal-based, fermented Turkish beverage. Food Chemistry. 111 (4): 983 - 987. 